\title{
Correlation Between Transformational Leadership, Psychological Capital and Work Engagement
}

\author{
Dea Hansel Pugar ${ }^{1}$, Endang Parahyanti ${ }^{2}$ \\ ${ }^{1,2}$ Faculty of Psychology, University of Indonesia, Depok, Indonesia \\ E-mail:dea.hansel@ui.ac.id
}

\begin{abstract}
This research aims to study the effect of transformational leadership and psychological capital (PsyCap) on work engagement. The idea of this research derived from the phenomena in a startup company in which it has high turnover. To address this problem, one possible solution needs to be taken is by increasing work engagement. This is built on past studies which indicates work engagements could predict turnover intention (Saks, 2006). The participants of this research were 31 employees of startup companies in Indonesia. This was a quantitative research with regression analysis for hypothesis testing. Finally, the results showed that psychological capital (PsyCap) has a significant influence on work engagement and transformational leadership does not affect work engagement.
\end{abstract}

\section{Keywords: transformational leadership; psychological capital; work engagement}

\section{Introduction}

In recent years, startup companies (i.e., newly technology-based entrepreneur company) rapidly grow. To win the very competitive environment in this industry, startup companies need employees who are mentally tied to their work and are willing to do the best they can to support the success of the organization. The employee's attachment to his work could be explained by the term work engagement. When employees engage, they are aware of their responsibility to achieve goals and motivate their co-workers to participate in the achievement of organizational goals. Moreover, the previous research revealed that higher engagement rates significantly reduce turnover intention (Maslach et al., 2001; Saks, 2006). In an interview, a CEO of a startup company in Bandung stated that the turnover rate of employees in the company is high, reaching $40 \%$ in 2016.

Some factors that can facilitate the influence work engagement are explained in JD-R (Job DemandResources) model theory (Bakker \& Demerouti, 2008). Bakker (2011) stated that job resources and personal resources directly affect work engagement. There is an interaction between job resources and personal resources. Leadership is one of the factor in job resources, so that influence engagement (Bakker, 2011). Previous studies showed that engagement would be higher when there are inspirational leaders in the organizations (Anitha, 2014). Leaders have a responsibility to communicate every small effort every employee should do to support organizational success. Such leadership is known as transformational leadership that can be defined as a leader who exhibits behaviors that can inspire and motivate individuals to produce performance beyond the expectations (Bass \& Riggio, 2006).

Psychological capital (PsyCap) also influence engagement, because it is one of the factor in personal resources (Schaufeli \& Taris, 2014). Self-efficacy, hope, optimism, and resilience, that four dimensions in personal resources are also dimensions in PsyCap. PsyCap is defined as a positive psychological state of the individual to grow (Luthans et al., 2007; Waltz, 2009, in Gooty et al., 2009). Luthans (2007) stated that PsyCap is a positive psychological resource that can be affected by some variables in organization and leadership. Bakker (2011) also stated that personal resources (i.e., PsyCap) correlates to job resources (i.e., leadership). Based on the theory of JD-R model, researchers assumed that PsyCap also has an impact on performance outcomes, like work engagement. 
Based on the previous description, thus in this study, researchers interested to examine the relationship between transformational leadership, psychological capital, and work engagement. We interested in finding that relationship in a startup company for the first time. The first formulation of the proposed problem was whether transformational leadership has a direct influence on psychological capital and work engagement. The second problem was whether psychological capital has a direct influence on work engagement.

Work engagement. Although researchers and practitioners have not all agree on the exact definition and measurement of work engagement, it is often defined as a mind-filled state of positive work. It was characterized by vigor, dedication, and absorption (Schaufeli, Salanova, and Bakker, 2006). Vigor means that workers have high energy levels, mental endurance, and persistence. Dedication means workers are enthusiastic, inspiring, proud, and liking challenges at work. Meanwhile, absorption means that the workers have a high level of concentration, focus, intensity, and soluble in work.

Transformational leadership. Transformational leadership is defined as a leadership in which the leader can inspire and motivate individuals to produce performance beyond the expectations. Previous studies show that transformational leadership positively predicts the outcomes from employees and organizations (Bass, 1985; Aryee, Walumba, Zhou, and Hartnell, 2012). Their study showed that transformational leadership would be positively related to employee work engagement, experienced meaningfulness of work, and experienced responsibility for work outcomes, respectively (Aryee, Walumbwa, Zhou, and Hartnell, 2012).

Bass and Riggio (2006) explained that transformational leadership is reflected in four characteristics, namely idealized influence, inspirational motivation, intellectual stimulations, and individualized consideration. Idealized influence/charisma leaders show abilities to provide meaningful missions and earned the respect and appreciation of the members. Inspirational motivational leaders are able to communicate an exciting vision, establishes an interesting objective, and demonstrates confidence that a member can achieve certain objectives. Leaders with intellectual stimulation show capacity to stimulate its members to be innovative and creative by questioning assumptions and taking new approaches in old situations. Individualized consideration leaders treat members as individuals, not just as group members, and gives special attention to their need for development by acting as a teacher or a coach.

Psychological Capital. Psychological capital is individual psychological powers, perceptions, attitudes toward work, and a general view of life (Luthans, Youssef, and Avolio, 2007). According to the positive psychology literature, positive organizational behavior is intended to identify the newly emerging focus of a positive approach to developing and managing human resources in the workplace (Luthans, Youssef, and Avolio, 2007). Luthans (2007) identified four individual capacities that are individual whose psychological capital; self-efficacy, hope, resilience, and optimism. PsyCap may vary within individuals based on contextual conditions (e.g, inspirational leaders) and individual characteristics (e.g, traits, physical health; Luthans, Youssef, and Avolio, 2007).

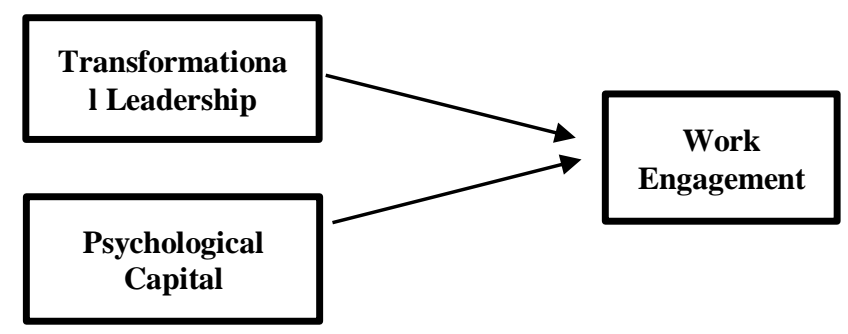

Figure 1. Research Framework

Built on past studies, here we keen to understand the role of transformational leadership and psychological capital on work engagement. There has been indeed some studies which indicate that those factors independently can contribute in work engagement. Moreover, the theory of JD-R model explains how the job resources (i.e., transformational leadership) and personal resources (i.e., psychological capital) directly affect to work engagement (Bakker \& Demerouti, 2008; Bakker, 2011). However, there has not studies that attempt to understand their effects simultaneously. The factors that can influence on work engagement are leadership, job demand, and job resources.

\section{Methods}

Sample. In this study, the research population are the employees who work in startup companies in Indonesia. The requirement of the research participants are: employees who work at a startup 
company for at least one year, minimum age 20 years, and have earned a bachelor degree from a university/college.

Table 1

Respondent Demographic Data

\begin{tabular}{lrcc}
\hline & & F & Percentage \\
\hline Gender & Man & 17 & $54.8 \%$ \\
Wge (year) & & & $45.2 \%$ \\
& $20-24$ & 11 & $35.5 \%$ \\
& $25-29$ & 12 & $38.7 \%$ \\
Education & 30 & 8 & $25.8 \%$ \\
& & & \\
Working (year) & $\mathrm{S} 1$ & 29 & $93.5 \%$ \\
& $\mathrm{~S} 2$ & 2 & $6.5 \%$ \\
& $1-2$ & 13 & $41.9 \%$ \\
& $3-4$ & 10 & $32.3 \%$ \\
& 5 & 8 & $25.8 \%$ \\
& & & \\
& & & \\
& & & \\
& & & \\
& Jakarta & 21 & $67.8 \%$ \\
& Tangerang & 5 & $16.1 \%$ \\
& Bandung & 4 & $12.9 \%$ \\
& Bogor & 1 & $3.2 \%$ \\
\hline
\end{tabular}

Research Design. This study is a quantitative research. Data were analyzed with linear regression using SPSS program.

Instrument and Measurement. In this study, the questionnaire/surveys that consist of four different sections were used. The first questionnaire consisted of participant demographic data; initials name, gender, age, job tenure, and workplace location. Three other questionnaires were questionnaires on the variables studied, namely work engagement, transformational leadership, and psychological capital.

Work engagement. Utrecht Work Engagement Scale (UWES-9) was used as the measurement of work engagement. The UWES-9 measures the three dimensions of work engagement namely vigor, dedication, and absorption. We asked participants to rate each statement according to their own circumstances using seven-point Likert scales ranging from 0 (never) to 6 (always). A higher score means a higher level of individual work engagement. Cronbach's alpha coefficient of the UWES-9 measuring instrument in this research was .847 .

Transformational leadership. The MLQ Form 5X (Avolio \& Bass, 1995) was used to measure transformational leadership. MLQ consisted of 20 items measured based on the four dimensions of transformational leadership, namely idealized influence, inspirational motivation, intellectual stimulation, and individualized consideration. Participants were asked to rate their immediate supervisor about how often the boss indicates the behavior mentioned in the statements. The response of the participants was based on a fivepoint Likert scale ranging from 1 (never) to 5 (always). Cronbach's alpha coefficient of measuring instrument MLQ transformational leadership in this study was .932 .

PsyCap. In measuring PsyCap, Psychological Capacity Questionnaire (PCQ) was used. It consisted of 24 items and was a self-report questionnaire (Luthans et al., 2007). Each item of the PCQ was rated using a six-point Likert scale ( $1=$ strongly disagree, $6=$ strongly agree $)$. The assessment of PCQ measurements was derived from assessments of self-described participants. It consisted of hope, optimism, resilience, and selfefficacy components. Cronbach's alpha coefficient of PCQ measuring instrument in this study is .90 with three items discarded since their corrected item-total correlations value were below .3.

Procedure. Methods of data retrieval were obtained through an online questionnaire distributed to each of the researcher's contacts included in the participant criteria. After that, the researchers asked for help from those acquaintances to spread the link of the questionnaire online to his/her colleagues. Therefore, the sampling technique that was used in this research is non-probability sampling (snowball sampling). Snowball sampling was used by asking the participants whether he/she has the friends that meet the criteria.

\section{Results}

Table 2

Descriptive Statistics and Variable Correlation

\begin{tabular}{lccccc}
\hline & M & SD & WE & PsyCap & TL \\
\hline (WE) & 42.35 & 6.06 & & $.700^{* *}$ & $.375^{*}$ \\
(TL) & 83.97 & 9.67 & $.375^{*}$ & $.390^{*}$ & \\
(PsyCap) & 102.9 & 10.17 & $.700^{* *}$ & & $.390^{*}$ \\
\hline
\end{tabular}


Table 3

Variable Regression Result

\begin{tabular}{lccc}
\hline & \multicolumn{4}{c}{ Work engagement } \\
\cline { 2 - 4 } Model & $\mathrm{p}$ & $\beta$ & $\Delta \mathrm{R} 2$ \\
(TL) & .000 & & .433 \\
(PsyCap) & .155 & .209 & \\
\hline
\end{tabular}

Table 2 presented the information on descriptive statistics and correlations between research variables. Table 3 presented the information on the effect test results (regression) of two independent variables (transformational and PsyCap) on the dependent variable (engagement).

In this study, first, we tested the model with transformational leadership and PsyCap together to work engagement. In Table 3 , the results showed the model can explain ...\% (please ad R square value). variance in the work engagement. PsyCap was found as the only variable that has a significant contribution in work engagement $(\beta=$ $.60, \mathrm{p}<.001)$. This is in line with the theory that personal resources affect the engagement (Albrecht et al., 2015). However, transformational leadership has no significant effect on employee work engagement $(\beta=.21, p=.155)$.

Table 4

Transformational Leadership Regression Result

\begin{tabular}{cccc}
\hline & \multicolumn{4}{c}{ Work engagement } \\
\cline { 2 - 4 } Model & $\mathrm{p}$ & $\beta$ & $\Delta \mathrm{R} 2$ \\
(TL) & .037 & & .112 \\
\hline
\end{tabular}

Meanwhile, when PsyCap was excluded from the model, transformational leadership emerged as a significant predictor of work engagement $(\beta=.38$, $\mathrm{p}=.037$ ). It can explain $11.2 \%$ variance in work engagement.

\section{Discussion \& Conclusion}

Discussion. The results of the study indicated that the transformational leadership has a significant effect, but the effect is reduced when the effect is measured together with psychological capital. It means that psychological capital has a more powerful effect on work engagement than transformational leadership. This finding might be attributed to explain that employee can still engage in their work, no matter who the leaders are and how they lead.

The present study provided some theoretical and practical contributions. Theoretically, psychological capital will predict work engagement. The employee that has higher PsyCap will show more engage in their work. Practically, present study offered the idea of to increase PsyCap in startup companies. As suggested earlier, startup company face the problems of high turnover. In fact, to compete with highly environment, a company needs a stability, one of them is by workers who are highly engaged in their works. To obtain such goal, the present study indicates that startup companies need to increase PsyCap. Previous study found that there are some ways to increase PsyCap. First, the companies need to create an environment that makes employee can set their goal in their work and belief that they can overcome obstacles to achieve those valued goals. Second, the companies need to create an environment that makes employee have a good time when working and participating in the company. Bakker (2011) stated that engaged employee have the tendency to believe that they will generally experience good outcomes in life (optimistic) and believe they can satisfy their needs by participating in roles within the organization (self-esteem).

In an age of competitive business development, if a company could create an environment that was able to encourage and enhance PsyCap (i.e., selfefficacy, hope, optimism, and resilience), it will help companies to retain human resources (Liao, $\mathrm{Hu} \&$ Chen, 2017). It will also help companies to become more competitive in attracting, training new talents, investing, developing, managing, and using psychological capital. Thus it is able to provide a sustainable competitive advantage to the company. In addition, with the increase of PsyCap will also increase employee engagement.

To increase employee engagement, employees need to feel secure, confident, diligent, and flexible, and in this case, empowering behavior of leaders play an important role in improving the psychological capital of employees (Park, Kim, Yoon \& Joo, 2017). Therefore, the learning and development process in the workplace can incorporate the elements of empowering leadership training and coaching or mentoring arrangements. After that, the leaders can become facilitators for their employees to improve their PsyCap through PsyCap Intervention (PCI): 1) determining the goals and steps of achievement in working together; 2) analyze what might be an obstacle to achieve goals and how to minimize barriers; 3) leaders play a role to arouse and support employees so that they can take steps to 
achieve goals with confidence, for example by persuading that they can succeed, becoming role models for them, providing positive feedback, etc.; 4) train the employees to anticipate and overcome setbacks or failures that may occur in achieving goals, so that they can bounce back from the failures and move on to the next step (Luthans et al., 2006).

There are some limitations in this study, namely: 1) the number of respondents was still small; 2) the type of work of startup employees was very diverse and unrestricted; 3) this study used selfreport questionnaires to be highly biased; 4) it has not seen the correlation of demographic data; 5) The relationship/influence indirectly between variables has not seen. Given these limitations, further research should address these issues, namely by 1) increasing the sample of research;2) the type of startup work in this study has to be controlled; 3) questionnaires should be integrated with interviews, observations, and appraisals from superiors/ subordinates/peers; 4) correlate the results with demographic data; 5) it should be added the moderation / mediation between independent and dependent variables.

Conclusion. Based on the results of the study on the relationship between transformational leadership, psychological capital, and work engagement on employees who work at startup companies, it was found that 1) transformational leadership affect employee work engagement if only PsyCap was not included, because PsyCap effect is too weak ; 2) The psychological capital of employees has a significant influence on employee work engagement. Through the results of these studies, it can be said that the higher of the psychological level of employee startup, then the higher the level of employee work engagement.

\section{References}

Albrecht, S. L., Bakker, A. B., Gruman, J. A., Macey, W. H., \& Saks. A. M. (2015). Emplovee engagement. human resource management practices and competitive advantage: An integrated approach. Journal of Organizational Effectiveness: People and Performance, 2(1), 7-35.

Anitha. J. (2014). Determinants of emplovee engagement and their impact on emblovee performance. International Journal of Productivity and Performance Management, 63(3), 308-323.

Aryee, S., Walumbwa, F. O., Zhou, O., \& Hartnell, C. A. (2012). Transformational leadership, innovative behavior, and task performance: Test of mediation and moderation processes. Human Performance, 25, 1-25.
Bakker, A. B. (2011). An evidence-based model of work engagement. Current Directions in Psychological Science, 20(4), 265-269.

Bakker. A. B.. \& Demerouti. E. (2008). Towards a model of work engagement. Career Development International, 13(3), 209-223.

Bass. B. M.. \& Riggio. R. E. (2006). Transformational Leadership. London: Lawrence Erlbaum Associates Publishers.

Gootv. J.. Gavin. M.. Johnson. P. D.. Frazier. M. L.. \& Snow. D. B. (2009). In the eves of the beholder transformational leadership, positive psychological capital, and performance. Journal of Leadership \& Organizational Studies, 15(4), 353-367.

Liao, S. S., Liao, S. S., Hu, D. C., Hu, D. C., Chung, Y. C., Chung. Y. C.. ... \& Chen. L. W. (2017). LMX and emplovee satisfaction: Mediating effect of psvchological capital. Leadership \& Organization Development Journal, 38(3), 433-449.

Luthans. F.. Youssef. C M.. \& Avolio. B J. (2007). Psvchological Capital: Developing The Human Competitive Edge. New York: Oxford University Press.

Maslach, C., Schaufeli, W. B., \& Leiter, M. P. (2001). Job burnout. Annual Review of Psychology, 52(1), 397-422.

Park, J. G., Kim, J. S., Yoon, S., \& Joo, B. K. (2017). The effects of empowering leadership on psychological wellbeing and iob engagement: The mediating role of psvchological capital. Leadership \& Organization Development Journal, 38(3), 350-367.

Saks. A. M. (2006). Antecedents and consequences of emplovee engagement. Journal of Managerial Psychology, 21(7), 600-619.

Schaufeli, W. B. \& Bakker, A. B. (2004). Job demands, job resources. and their relationship with burnout and engagement: A multi-sample study. Journal of Organizational Behavior, 25, 293-315.

Schaufeli, W. B., Salanova, M., \& Bakker, A. B. (2006). The measurement of work engagement with a short auestionnaire. Journal of Educational and Psychological Measurement, 66, 701-716.

Schaufeli, W. B. \& Taris, T. W. (2014). A critical review of the iob demands-resources model: Implications for improving work and health. Bridging Occupational, Organizational and Public Health, 43-68. 